\title{
Evaluation of musculoskeletal complications in the patients with brucellosis
}

\author{
Narges Najafi ${ }^{1}$, Alireza Davoudi ${ }^{2}$, Atefeh Tayebi ${ }^{3}$, Samaneh Rouhi ${ }^{4}$, Babak Mokhtarpour ${ }^{5}$, Fatemeh
} Ahangarkani ${ }^{6}$

1. Associate Professor, Antimicrobial Resistance Research Center, Communicable Diseases Institute, Mazandaran University of Medical Sciences, Sari, Iran. ORCID ID: 0000-0001-6603-6549.

2. Associate Professor, Antimicrobial Resistance Research Center, Communicable Diseases Institute, Mazandaran University of Medical Sciences, Sari, Iran., (Corresponding author), Tel: +981142318231, Email: eiy_iran@yahoo.com, ORCID ID: 0000-0002-1170-2206.

3. Infectious Diseases Specialist, Antimicrobial Resistance Research Center, Communicable Diseases Institute, Mazandaran University of Medical Sciences, Sari, Iran. ORCID ID: 0000-0001-9039-2535.

4. Ph.D. of Medical Bacteriology, Clinical Research Development Unit of Rouhani Hospital, Babol University of Medical Sciences, Babol, Iran. ORCID ID: 0000-0003-0160-0924.

5. General Practitioner, Antimicrobial Resistance Research Center, Communicable Diseases Institute, Mazandaran University of Medical Sciences, Sari, Iran. ORCID ID: 0000-0002-7467-242X.

6. Assistant Professor, Antimicrobial Resistance Research Center, Communicable Diseases Institute, Mazandaran

University of Medical Sciences, Sari, Iran. ORCID ID: 0000-0002-3629-7446

\section{ABSTRACT}

Background and Aim: One of the most common complications of brucellosis is its skeletal manifestations. This study was performed to identify the different types of skeletal manifestations in the patients with brucellosis.

Materials and Methods: We reviewed records of the patients with skeletal complications of brucellosis who had been admitted to the infectious diseases ward of Razi Hospital in Qaemshahr from 2011 to 2017. Using SPSS 21 software, data were analyzed by t-test and chisquare $(\mathrm{p} \leq 0.001)$.

Results: In 300 patients with brucellosis, the most frequent cause of referring to the hospital was fever $(82.33 \%)$. The most, common skeletal complication was lumbar spondylosis. The mean value for hemoglobin was $11.50 \pm 1.57 \mathrm{gr} / \mathrm{dl}$ in women and $12.34 \pm 1.54 \mathrm{gr} / \mathrm{dl}$ in men. Elevated alkaline phosphatase (97\%) was the most common laboratory finding. This disease was more common in men than in women which showed a statistically significant difference $(\mathrm{p} \leq 0.001)$. The mean erythrocyte sedimentation rate was $52.78 \pm 29.15$ millimeters per hour in the women $(\mathrm{p} \geq 0.001)$.

Conclusion: Fever and back pain were the most common causes of referring to the hospital. The most common articular bone complication was spondylosis, which was more common in the middle-aged patients. Therefore, brucellosis should be considered as a differential diagnosis in the patients with long-standing fever and also in those with low back pain and arthralgia.

Keywords: Complications, Musculoskeletal, Patients, Brucellosis

Received: Mar 3, 2020

Accepted: Sep 7, 2020

How to cite the article: Narges Najafi, Alireza Davoudi, Atefeh Tayebi, Samaneh Rouhi, Babak Mokhtarpour, Fatemeh Ahangarkani. Evaluation of musculoskeletal complications in the patients with brucellosis (Short report). SJKU 2021;26(2):57-63.

Copyright $\odot 2018$ the Author (s). Published by Kurdistan University of Medical Sciences. This is an open access article distributed under the terms of the Creative Commons Attribution-Non Commercial License 4.0 (CCBYNC), where it is permissible to download, share, remix, transform, and buildup the work provided it is properly cited. The work cannot be used commercially without permission from the journal 


\section{بررسى عوارض سيستم حر كتى بيماران مبتلا به بروسلوزيس (كزارش كوقاه)}

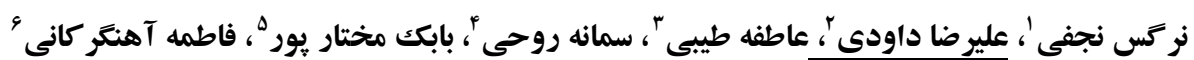

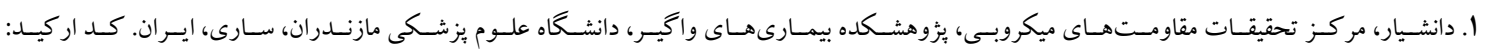
.........1-99. r-9DF9

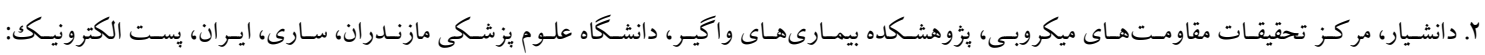
eiy_iran@yahoo.com

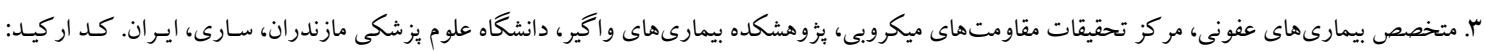
......... 1-q.rq-rordo

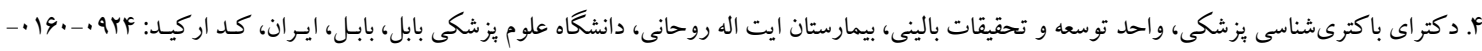
ه. يزشكى عمومى، مركز تحقيقات مقاومتهاى ميكروبى، ئزوهشكده بيمارىهاى واگير، دانشكاه علوم يزشكى مازندران، سارى، ايران. كد اركيد: ........ Y VFG - YFrX

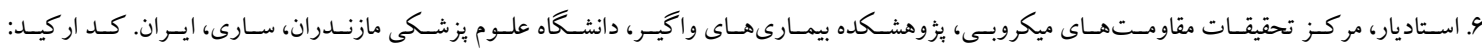
........r-rGYq-VFFG

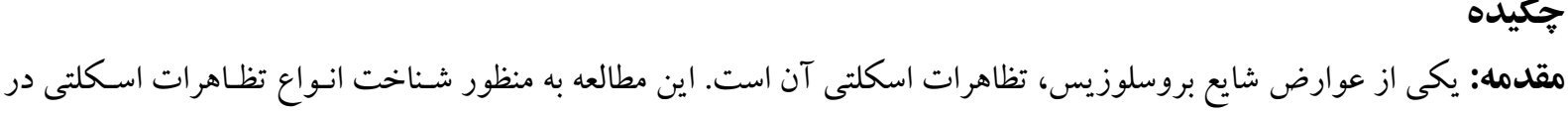
بيماران مبتلا به بروسلوزيس انجام شده است.

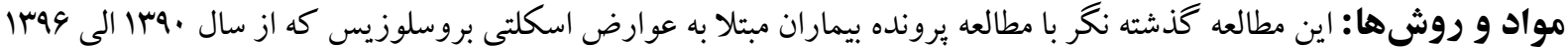

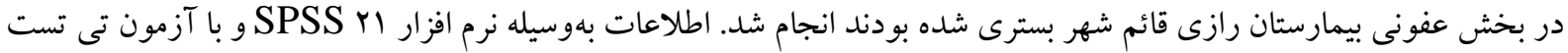
و كاى دو تجزيهو تحليل شدند (1./.

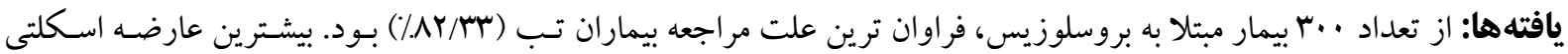

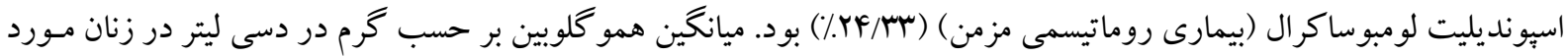

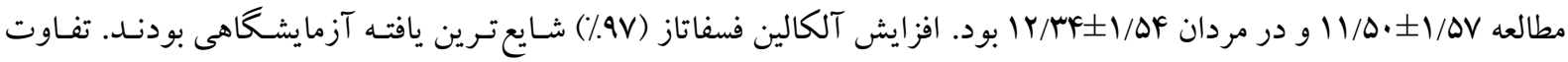

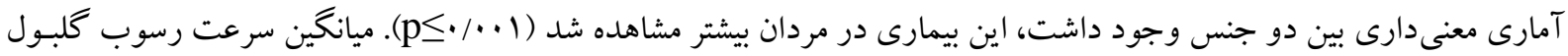

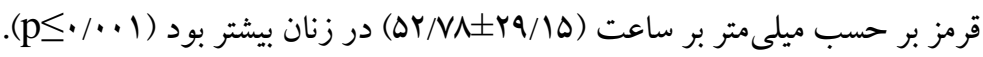
نتيجه كيرى: تب و كمردرد شايع ترين علت در بيماران بود. شايع ترين عارضه استخوانى - مفصلى اسبونديليت بود كه در بيمـاران

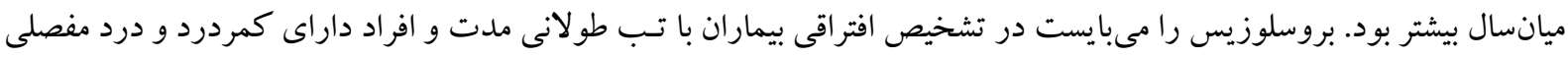
مورد بررسى قرار داد. كلمات كليدى: عوارض، سيستم حركتى، بيماران، بروسلوزيس

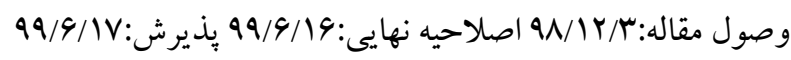


آزمايش Y- مر كايتواتانول ، IgG مداخله نموده كه از نقطه

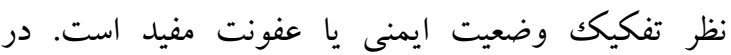
مواردى كه آنتىبادىهايى وجود داشته باشند و آكلو تيناسيون واضح ايجاد نمىنمايد آزمايش كومبس انجام

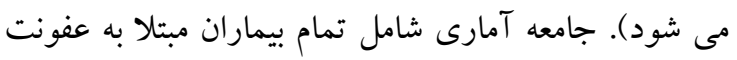

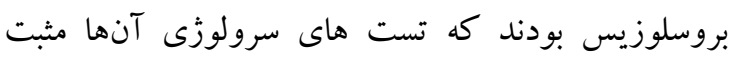
اعلام شده بود (نمونه يرى غير تصادفى سهميهاى). معيارهاى ورود شامل تمامى بيماران بسترى شده از اول

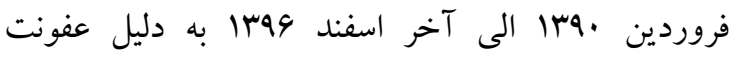
بروسلوزيس (طبق بروتكل ملى مبتنى بر شواهد بالينى و

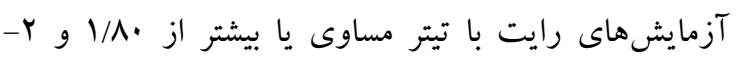
مركايتواتانول با تيتر مساوى يا بيشتر از ••l/4) در بيمارستان رازى شهرستان قائم شهر، استان مازندران بود (ه). جمع آورى اطلاعات: فرم جمع آورى اطلاعات بر اساس

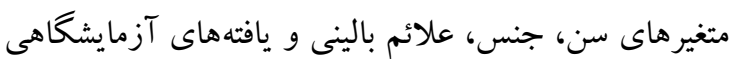
طراحى شد. در اين تحقيق يرونده بيماران مورد بررسى قرار

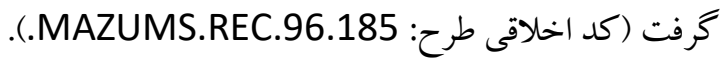
روش آمارى: پِ از جمع آورى اطلاعات، داده ها وارد نرم

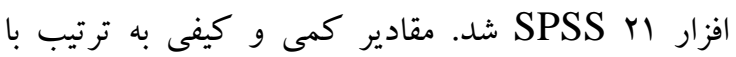

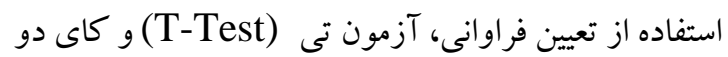
Sوquare) (Chi$(\mathrm{p} \leq \bullet / \cdot \cdot)$

يافته ها

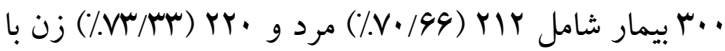

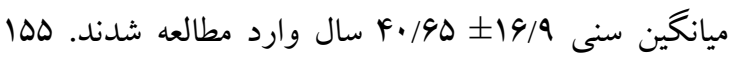

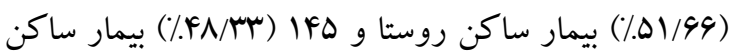

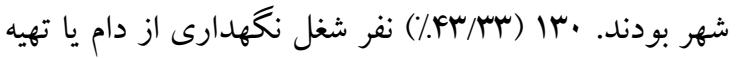
لبنيات و •IV (V9/94.ه4) نفر سابقه مصرف لبنيات محلى داشتند. در 9 (ז/٪) نفر سابقه ابتلا به بروسلوزيس در خانواده

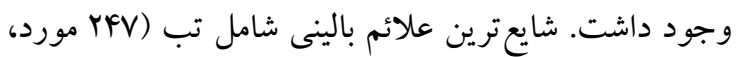
rr/Ar/) و كمترين مورد مربوط به سفتى گرددن و و تورم

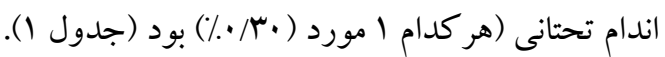

\section{مقدمه}

سالانه هزاران مورد جديد از بروسلوزيس در سراسر جهان كزارش شده است. بروز سالانه آن به ازاى هر ميليون جمعيت در ايران سعودى r/F/F و در عراق rVN/F است (1). گونهاى بروسلا باكترى هاى كو كوباسيل هاى گرم منفى مىباشند

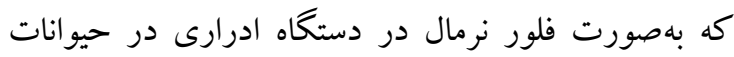

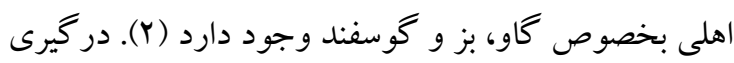
سيستم حركتى شايعترين عارضه بروسلوزيس است (r). نحوه بروز عوارض سيستم حركتى بروسلوزيس مى تواند

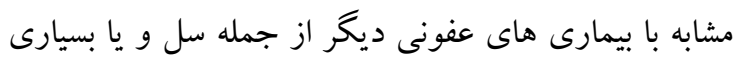

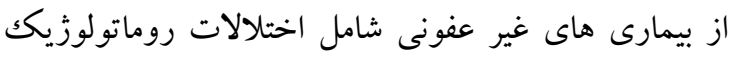

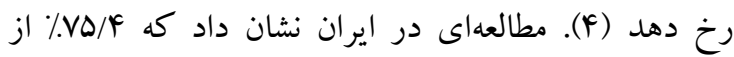
بيماران با بروسلوزيس مبتلا به روماتيسم مفصلى محيطى و ودران

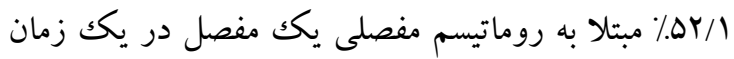

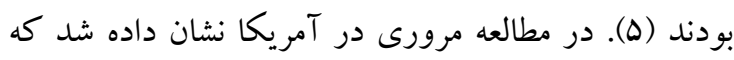

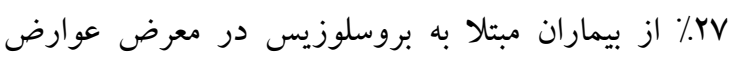

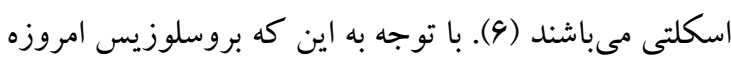

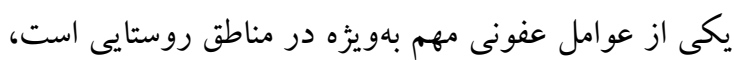

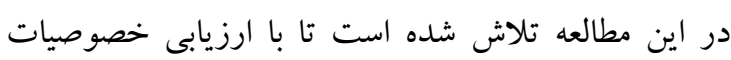
بالينى و باراكلينيك بيماران مبتلا به بروسلوزيس با عارضه

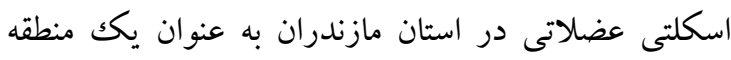

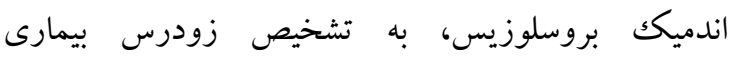
بروسلوزيس و عوارض سيستم حر كتى آن كمك نمايد.

\section{مواد و روش ها}

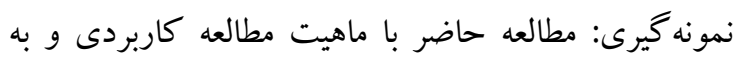

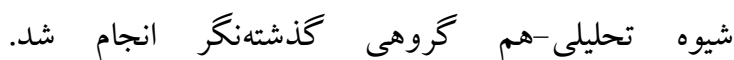

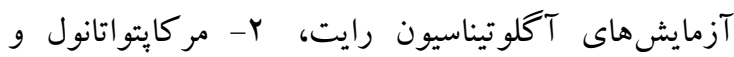
كومبس رايت به روش استاندارد انجام شد (آزمايش رايت

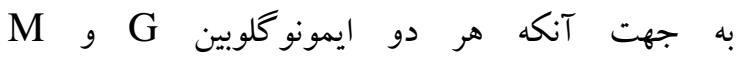
(Immunoglobulin G/M, IgG, IgM) دخالت دارد زودتر از ديخر آزمايش ها واكنش دارد. در 


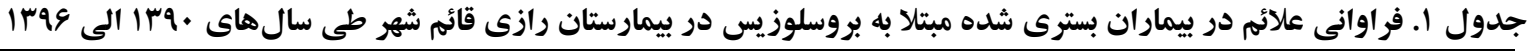

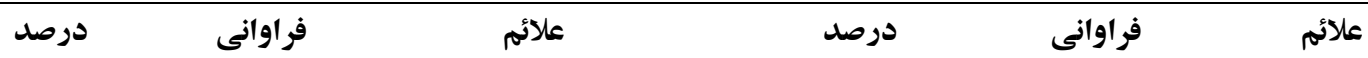

\begin{tabular}{|c|c|c|c|c|c|}
\hline س & ro & سرفه & سת/NT & YFV & تب \\
\hline$r$ & 9 & يبوست & $90 / 94$ & $19 V$ & تعريق \\
\hline
\end{tabular}

\begin{tabular}{|c|c|c|c|c|c|}
\hline r & 4 & 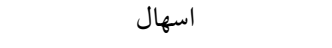 & $\Delta r / r$ & $10 \mathrm{~V}$ & 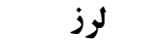 \\
\hline$r$ & 9 & 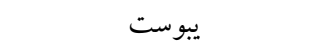 & $\Delta r / \mu r$ & $10 \mathrm{~V}$ & درد عضلانى \\
\hline 1 & $r$ & 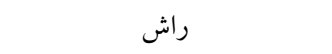 & kr & Irq & كمردرد \\
\hline 10 & FD & حساس به لمس نقطهاى مهرهها & Fi & Irr & كاهش اشتها \\
\hline
\end{tabular}

\begin{tabular}{|c|c|c|c|c|c|}
\hline 11 & 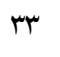 & محدوديت حر كت مفاصل & $r F$ & $1 . r$ & كاهش وزن \\
\hline f & ir & ورم طحال & ( & Va & سردرد \\
\hline r & 1. & تورم غدد لنفاوى & $r Y / r$ & $9 V$ & ضعف \\
\hline$r$ & 9 & تورم بيضهها & Tr/Tr & $9 V$ & درد مفصلى \\
\hline 1 & $r$ & بزرگى كبد & 10 & fo & تهوع \\
\hline$\cdot / \mu$ & 1 & سفتى گردن & 11 & 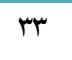 & درد شكم \\
\hline$\cdot / \mu$. & 1 & تورم اندام تحتانى & $1 / 94$ & Yq & استفراغ \\
\hline
\end{tabular}

هر كدام ץ (1\%) مورد، روماتيسم مفاصل كوجّك دست و

آرتريت آرنج هر كدام ب (1\%) مورد كزارش شد. آرتريت

مج يا، لكن، مج دست و شانه گز ارش نشد (شكل ( ).
بيشترين عوارض اسكلتى اسبونديليت لومبوساكرال (بيمارى روماتيسمى مزمن) س V (سM/YY\%) مورد و كمترين عوارض

اسبونديليت توراسيك و گردنى (بيمارى روماتيسمى مزمن)

شكل 1. فراوانى عوارض اسكلتى در بيمار ان بسترى شده مبتلا به بروسلوزيس در بيمارستان رازى قائم شهر طى سال هاى • وب ا الى Irag

$$
\text { توزيع فراوانى عوارض اسكلتى }
$$

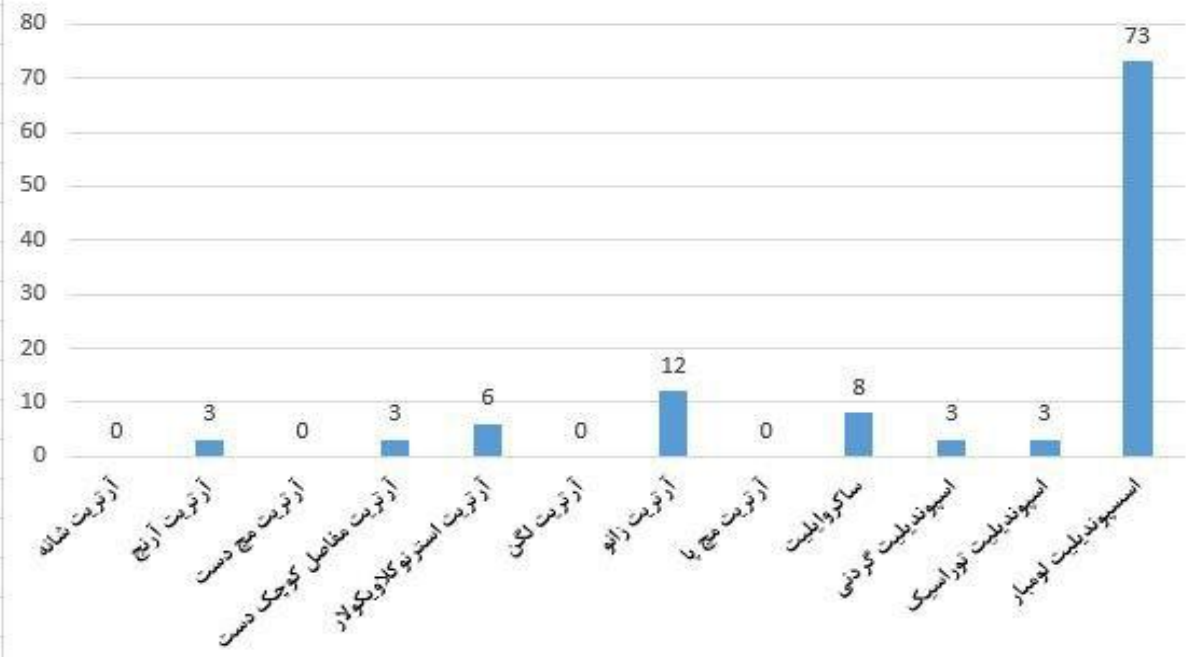

هجلم علمى دانشكاه علوه بِزشكى كردستان / دوره بيست و شش / ذرداد و تير معار/ه4-ع| 
41 عليرضا داودى

يافتهاى آزمايشگاهى بودند. تفاوت آمارى معنى دارى بين دو جنس وجود داشت، اين بيمارى در مردان بيشتر مشاهده

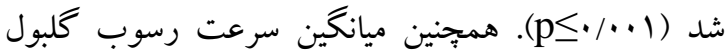
قرمز بر حسب ميلى متر بر ساعت در زنان هr/VA

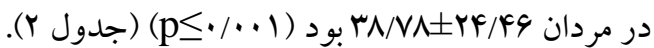

اطلاعات توصيفى حاصل از مطالعه حاضر نشان داد كه؛ ميانگين همو گلوبين بر حسب گرم در دسى ليتر در زنان

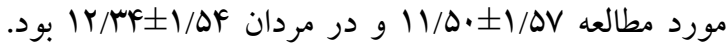

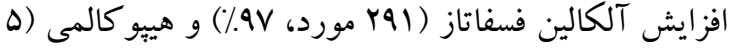
مورد، 199/1) به ترتيب شايعترين و كمترين موارد

جدول r. فراوانى يافتهاى آزمايشكاهى در بيماران بسترى شده مبتلا به بروسلوزيس در بيمارستان رازى قائم شهر طى سالهاى

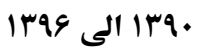

\begin{tabular}{|c|c|c|c|c|c|}
\hline درصد & فراوانى & نتايج & درصد & فراوانى & نتايج \\
\hline$\Delta$ & 10 & كاهش سديم خون & $\Delta 1$ & lor & كمخونى \\
\hline $4 / 94$ & if & افزايش سديم خون & $\mid f / \mu r$ & kr & كاهش گلبول سفيد \\
\hline \multirow[t]{2}{*}{$r r / 99$} & 91 & افزايش آسيارتات & IV & 01 & افزايش كلبول سفيد \\
\hline & & آمينو ترانسفراز & & & \\
\hline \multirow[t]{2}{*}{ rF/r } & vr & افزايش آلانين & $r F / M T$ & vr & اختلال پِلاكت خون \\
\hline & & آمينو تر انسفراز & & & \\
\hline \multirow[t]{2}{*}{$1 / 99$} & $\Delta$ & كاهش يتاسيم & $\wedge$. & YF. & افزايش سرعت \\
\hline & & & & & رسوب كلبول قرمز \\
\hline r & 1. & افزايش يتاسيم & $r$ & 9 & افزايش كراتينين \\
\hline & & & $9 V$ & ral & افزايش آلكالين \\
\hline
\end{tabular}

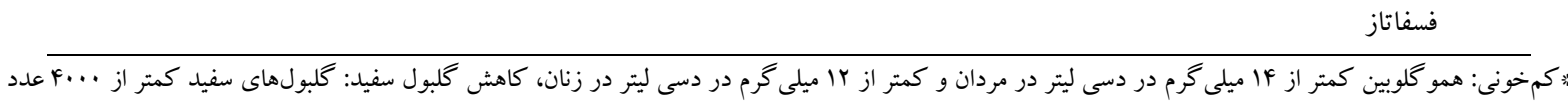

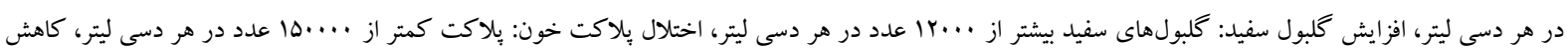

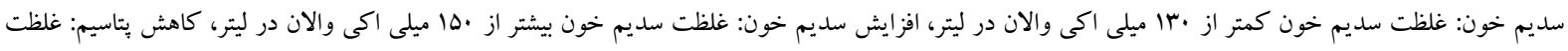

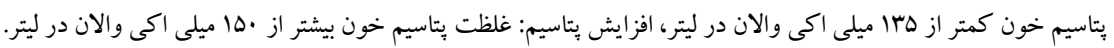

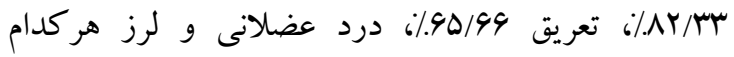

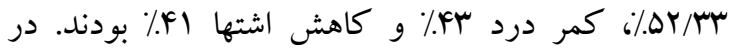

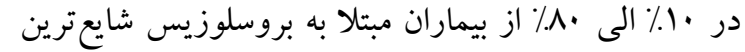
مطالعه ى كه در عربستان انجام شد، تب در . 1.؛ كمر درد عضو گرفتار دستخاه عضلانى اسكلتى است (Y). در اين در //V\%٪ و تعريق در 90\% از بيماران مشاهده شده كه هم

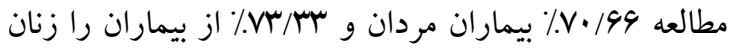
راستا با علائم بالينى مشاهده شده در مطالعه ما مى باشد (9). تشكيل مىدادند و ميانگين سنى افراد 19/9 همجنين در مطالعه ديخرى كه در ايران انجام شد، فراوان بود، مطالعه ما از نظر سن و جنسيت مشابه ساير مطالعات ترين علت اصلى مراجعه ى بيماران تب (VD٪) بود كه شايع

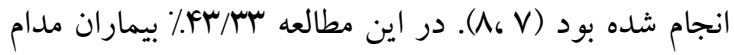
ترين يافته ى بـالينى در اين بيماران بوده است ( •(1). مطالعه در تماس بودند، در ساير مطالعات تماس شغلى YY\% و Yr/\% اى در تر كيه نشان داد كه تعريق 94\% گزارش شده است كه كزارش شد كه از مطالعه ما كمتر مى باشد. درصد بالاى هم راستا با نتايج مطالعه ما بود، تعريق زيـاد يكى از استفاده از لبنيات محلى نشان دهنده اين موضوع است كه

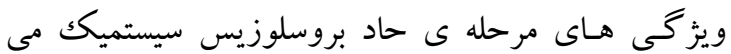
هم جنان راه اصلى انتقال بروسلا مصرف مواد لبنى آلوده است (ه). بيشترين علامت بالينى و نشانه ها شامل تب

هبلم علمى دانشكاه علوه بِزشكى كردستان / دوره بيست و شش / ذرداد و تير معام| 
سفيد بّ٪ و افزايش سرعت رسوب كلبول قرمز غير طبيعى IVV/A تب، لرز، سر درد، درد عضله و مفصل، خستكى و تعريق

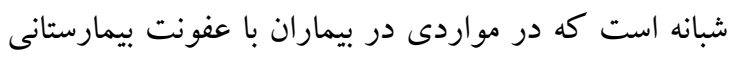

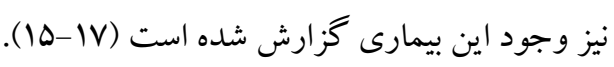

\section{نتيجه گيرى}

گستردگى نشـانه هـاى بـالينى در بروسـلوزيس و اختلال در

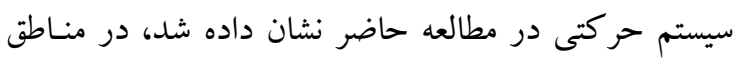
بومى در برخورد با هر بيمار با نشانه هاى متنوع و غير

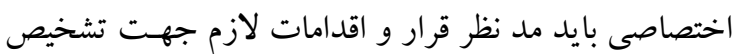
آن صورت گيرد.

\section{تشكر و قدردانى}

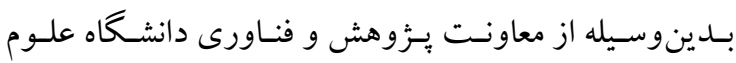

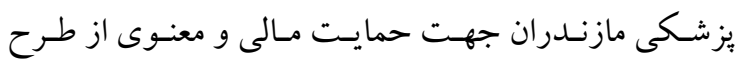

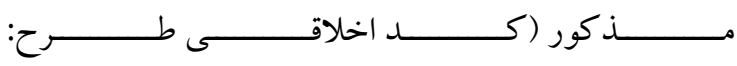
(IR.MAZUMS.REC.96.185 تقــدير و تشـكر بـــ

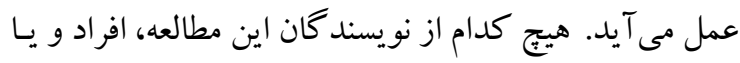

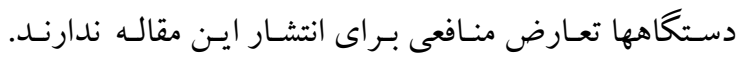

باشد. علت عدم مشاهده در همه ى بيماران احتمالاً به خاطر

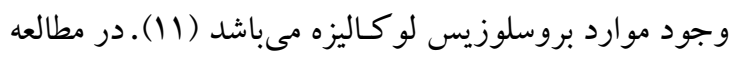

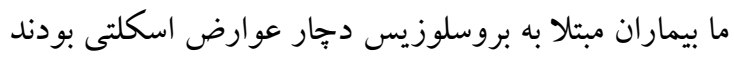

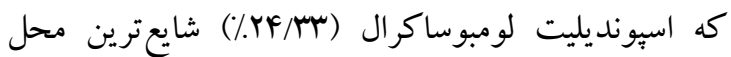
درگيرى بود. مطالعه مشابه در تركيه نيز شايعترين شكل

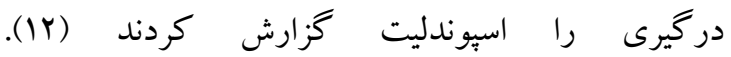
اسبونديلوديسكيت، آرتريت محيطى، التهاب ديسك مهرهاى، التهاب مايع مفصلى و التهاب تاندون از ديخر انديك

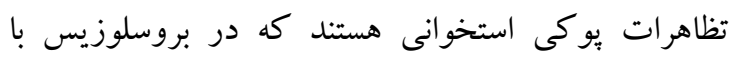
شيوع كمترى همراه هستند. آبسه إيدورال (عفونت ستون فقرات) يكك عارضه نادر از بروسلوزيس ستون فقرات است.

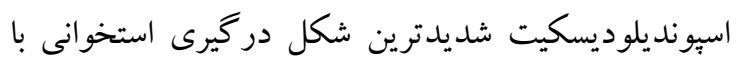

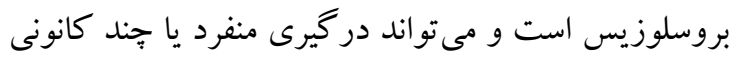

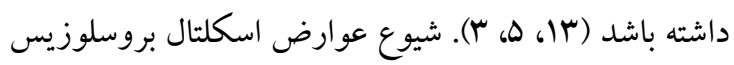

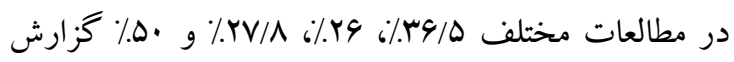

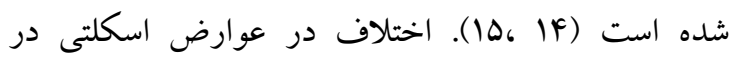
مطالعات مختلف شايد به دليل سوش هاى مختلف بروسلا در جوامع مختلف باشد و در مناطقى كه بروسلا ملينسيس ماسي

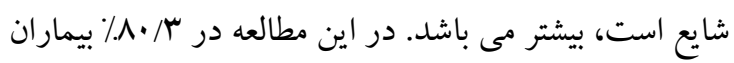

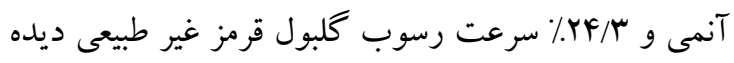

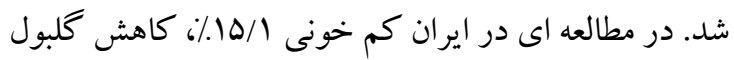

1.Esmaeilnejad-Ganji SM, Esmaeilnejad-Ganji SMR. Osteoarticular manifestations of human brucellosis: A review. World J Orthop. 2019;10(2):54-62.

2. Hashtarkhani S, Akbari M, Jarahi L, Etminani K. Epidemiological characteristics and trend of incidence of human brucellosis in Razavi Khorasan province. MUMS. 2015;58(9):531-8. [In Persian]

3. Bocanegra TS, Vasey FB. Rheumatologic manifestations of brucellosis. Rheumatol Int. 2011;31(6):721-4.

4. Colmenero JD, Ruiz -Mesa JD, Plata A, Bermúdez P, Martín-Rico P, Queipo-Ortuño MI, et al. Therapeutic approach, and outcome of brucellar vertebral osteomyelitis. Clin Infect Dis. 2008;46(3):426-33.

5. Ebrahimpour S, Bayani M, Moulana Z, Hasanjani Roushan MR. Skeletal complications of brucellosis: A study of 464 cases in Babol, Iran. Caspian J Intern Med. 2017;8(1):44-8. 
عليرضا داودى

6. Adetunji SA, Ramirez G, Foster MJ, Arenas-Gamboa AM.A systematic review and metaanalysis of the prevalence of osteoarticular brucellosis. PLoS Negl Trop Dis. 2019;13(1): e0007112.

7. E Elbeltagy K. An epidemiological profile of brucellosis in Tabuk Province, Saudi Arabia. East Mediterr Health J. 2001;7(4-5):791-8.

8. Tohme A, Hammoud A, El Rassi B, Germanos-Haddad M, Ghayad E. Human brucellosis. Retrospective studies of 63 cases in Lebanon. Presse Med. 2001;30(27):1339-43.

9. Malik GM. A clinical study of brucellosis in adults in the Asir region of southern Saudi Arabia. Am J Trop Med Hyg. 1997;56(4):375-7.

10. Hamzavi Y, Khademi N, Zadeh MMG, Janbakhsh A. Epidemiology of malt fever in Kermanshah province in 2011. J Kermanshah Univ Med Sci. 2014;18(2):114-21.

11. Namiduru M, Gungor K, Dikensoy O, Baydar I, Ekinci E, Karaoglan I, et al. Epidemiological, clinical and laboratory features of brucellosis: a prospective evaluation of 120 adult patients. Int J Clin Pract. 2002;57(1):20-4

12. Geyik MF, Gur A, Nas K, Cevik R, Sarac J, Dikici B, et al. Musculoskeletal involvement of brucellosis in different age groups: a study of 195 cases. Swiss Med Wkly. 2002;132(78):98-105.

13. Alian S, Davoudi Badabi A, Alaei A, Ahangarkani F, Javdani Yekta S. Comparison of clinical, laboratory and radiological features in patients with spondylodiscitis caused by tuberculosis and brucellosis. J Mazandaran Univ Med Sci. 2015; 25 (124): 213-7. [In Persian] 14. Gonzalez-Gay M, Garcia-Porrua C, Ibanez D, Garcia-Pais M. Osteoarticular complications of brucellosis in an Atlantic area of Spain. J Rheumatol. 1999;26(1):141-5.

15. Ariza J, Bosilkovski M, Cascio A, Colmenero JD, Corbel MJ, Falagas ME, et al. Perspectives for the treatment of brucellosis in the 21st century: the Ioannina recommendations. PLoS Med. 2007;4(12):e317.

16. Rezai M S, Bagheri-nesami M, Hajalibeig A, Ahangarkani F. Multidrug and Crossresistance Pattern of ESBL-producing Enterobacteriaceae Agents of Nosocomial Infections in Intensive Care Units. J Mazandaran Univ Med Sci. 2017; 26 (144): 39-49. [In Persian] 17. Abediankenari S, Ghasemi M, Nasehi MM, Abedi S, Hosseini V. Determination of trace elements in patients with chronic hepatitis B. Acta Med Iran. 2011;49(10):667-669. 